\title{
POTENTIALITY OF Theobroma cacao PEELS EXTRACT AS ADDITIVE ON WATER-BASED PAINT TO HYDROPHOBIC PROPERTIES
}

\author{
M. Ritaliah ${ }^{1}$, D. Dahlan ${ }^{1}$, and Y. Yetri ${ }^{2, *}$ \\ ${ }^{1}$ Department of Physics, Andalas University, Padang, Indonesia. \\ ${ }^{2}$ Politeknik Negeri Padang, Padang, Indonesia \\ *E-mail : yuliyetri@pnp.ac.id
}

\begin{abstract}
Cacao fruit consists of three major components: fruit, placenta and content. Cacao peels or commonly called as cacao pod/peel is waste with the largest proportion produced by cacao crops which have not been utilized sufficiently. The peel of cacao contains polyphenol compounds, one of which is tannin. It is an antinutrient compound that reduces the quality of materials by forming complex bonds with proteins. Tannin-protein complexes are occurred because of the hydrogen bonding, hydrophobic interactions, and covalent bonds between the compounds. Here, at this research, with the hydrophobic interaction in tannin, cacao peels extract is mixed as an additive in the water-based paint with concentration variations of $1 \%, 3 \%, 5 \%, 7 \%$ and $10 \%$, in order to increase the contact angle so that the paint is hydrophobic. Characterization was performed in accordance with Indonesian National Standardization 3546:2009 emulsion wall paint such as $\mathrm{pH}$ and density measurement, accelerated weather resistance, and alkaline resistance. Moreover, the contact angles and its surface morphology then were analyzed from the test results. It turned out that the water-based paint was hydrophobic on the addition of a $3 \%$ concentration additive with $127.89^{\circ}$ of contact angle before heating, and $127.26^{\circ}$ after warming in an accelerated weather resistance test. Hence, it was determined that cacao peels extract can improve the hydrophobic properties in water-based paint.
\end{abstract}

Keywords: Cacao peels extract; tannins; water-based paint; hydrophobic.

(C) RASĀYAN. All rights reserved

\section{INTRODUCTION}

Cacao (Theobroma cacao) is a significant crop in a number of tropical countries ${ }^{1}$. Its peels are the largest proportion of waste produced by cacao plants, which have not been maximally utilized ${ }^{1,2}$. Cacao peels is an agro-waste source where it becomes a satisfactory source on energy and protein containing 9-19\% protein and $13-26 \%$ crude fiber, $2400 \mathrm{kcal} / \mathrm{kg}$ metabolic energy, $4.6 \%$ fat, $0.61 \%$ calcium, and $0.06 \%$ phosphorus. Despite the nutritional content of the cacao peels are quite high, the cacao processing industrial waste also contains compound such as active alkaloids, theobromin alkaloid (3,7 dimethyl zanthine) which is a sedative, bioactive polyphenol, ie flavonoids or condensed tannins like anthocyanins, tannins, catechins, leukoantocyanidins and other compounds ${ }^{3}$. As an addition, cacao peels has $5.78 \%$ polyphenol content. Widely known, polyphenols in plants can be advantageous as antioxidants ${ }^{4}$. The activity of the antioxidant compound in cacao fruits has a positive correlation with total polyphenol content ${ }^{5}$. One of the polyphenol compounds is tannin, also called as tannic acid and galicic acid, which is an antinutrient compound that reduces the material quality by forming complex bonds with protein. Tannin is an organic compound composed of a mixture of complex polyphenol compounds, constructed by $\mathrm{C}, \mathrm{H}$, and $\mathrm{O}$ elements, and often forms large polymers with greater than 2000 of molecular weight. Tannin can be colorless to yellow or brown, and has a 724,5 nm maximum wavelength. Tannin-protein complexes occurred because of the hydrogen bond, hydrophobic interaction, and covalent bond among the compounds. With the presence of a hydrophobic bond, denaturation is going to be occured and ultimately disrupted cell metabolism.

This hydrophobic bonds make tannin becoming growth inhibitors, so that many microorganisms can be inhibited $^{6}$. In Indonesia, the development of the exterior and interior paint industry is increasing. The

Rasayan J. Chem., 11(3), 1277-1285(2018)

http://dx.doi.org/10.31788/RJC.2018.1134017

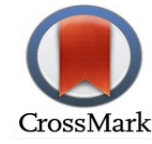


increasing demand for paint nowadays is in line with the expanding of the domestic property market. The paint producers continue to improve the quality of paint produced. Water-based paint is also called emulsion paint, where there is an emulsion between water and oil in its formulation. Emulsions are a type of colloid with dispersed phases in the form of liquids in solid, liquid, and gas dispersants. Moreover, within each component emulsion, there is emulsifier in the form of surfactant. Components or constituents of the paint consist of binders (resins), pigments, solvents, and additives. Additives are the ingredients added into the paint to add properties or properties of the paint in improving the quality of the paint. In addition to liquids, pigments and binders, a paint may contain one or more additives that serve to improve performance and is usually used in very small amounts ${ }^{7}$.

Paint it self is a material where it is fluid liquid at room temperature, and it will dry forming a solid layer when applied on an object surface ${ }^{8}$, Water-based wall paint uses emulsion polymerization principle where the water is as the dispersion phase, and the hydrophilic extender is an as dispersed phase. In emulsion paint, the dispersing phase is the liquid in the paint that is generally a water-based paint. The paint composition consists of $45 \%$ pigment, $35 \%$ binder, $15 \%$ solvent, and $5 \%$ additive. A good quality paint products must reach the required quality standards. Usually, the better the quality of the wall paint the higher the price in the market. The quality of the paint sold must meet the standards referring to Indonesian National Standardization (SNI) 3564:2009. In addition to standard quality assurance, it is also required reducing production costs in order to develop the paint industry 9 .

Most of the paint is hydrophilic and tends to be contaminated by pollutants in the water ${ }^{10}$, which generally uses inorganic substances to improve hydrophobic property such as silica and $\mathrm{TiO} 2^{11}$. With the hydrophobic interaction in tannins, cacao peels extracts can be utilized as organic additives in water-based paint, so this water-based paint possesses the eco-friendly hydrophobic property and can improve the paint quality. In this study is expected to be ably analyzing the effect of the addition of cacao peels extract to hydrophobic properties on water-based wall paint, analyze the resistance of the sample to the weather, and compare the physical properties obtained from a mixture of water-based paints with cacao peels extracts with emulsion wall paint SNI 3564:2009.

\section{Material and Methods}

\section{EXPERIMENTAL}

Raw materials in this research were water-based paint and cacao peels extract from F1 Jember cacao species planted in Piobang District Guguk Sub-district Limapuluh Kota Sumatera Barat Indonesia, and $\mathrm{NaOH} 0.1$ $\mathrm{N}$. While the equipment used were: MD 2800x optical microscope, $50 \mathrm{ml}$ pycnometer, magnetic stirrer, glass substrate $(7.5 \mathrm{~cm} \times 2.5 \mathrm{~cm} \times 0.5$ inches), $16 \mathrm{MP}$ digital camera, accelerated weather resistance test kit, digital balance, hydrometer, digital $\mathrm{pH}$ meter, timer, measuring cups, dripper pipettes, spatulas, and stirrer bars.

\section{The process of Making Cacao Peels Extract}

The process of making cacao peels extract through several stages: the skin of cacao fruit cleaned from dirt and chopped until thin-sized, dried for 14 days. Once dry, grind to a powder. Dry powder is then macerated using ethanol $70 \%$ for five days. Maceration is done repeatedly and afterward filtered by using filter paper. Filter results in the form of filtrate concentrated with Vacuum Rotary Evaporator. Furthermore, the extracts that have been made are used as additives in water-based paints.

\section{Cacao Fruit Peels Extract}

The water-based paint was mixed with cacao peels extract additives with concentration variations of $1 \%$, $3 \%, 5 \%, 7 \%$, and $10 \%$ serving as additives. Then stir with a Magnetic Stirrer at $12 \mathrm{rpm}$ for 15 minutes. Soon after it was mixed perfectly, $\mathrm{pH}$ and density measurements were performed. Furthermore, the mixture was applied to a glass substrate with the size of $7.5 \mathrm{~cm} \times 2.5 \mathrm{~cm} \times 0.5$ inches using a brush. Right after the paint coating dried, the resistance alkali testing, contact angle, and morphology surface were conducted.

\section{Physical Characterization \\ Density}

Density is the relative ratio between the density of a substance and the pure water mass. Here, the density of the water-based paint was adjusted to the emission of emulsion paint SNI 3546:2009 at least $1.2 \mathrm{~g} / \mathrm{cm}^{3}$ using a pycnometer. 


\section{Contact Angle}

A surface hydrophobic can be determined by measuring the amount of contact angle formed on the surface of the test material. In this research, the contact angle was the angle formed by the sample surface with the fluid dropped onto it ${ }^{12}$. A series of angle photo tools can be seen in Fig.-1.

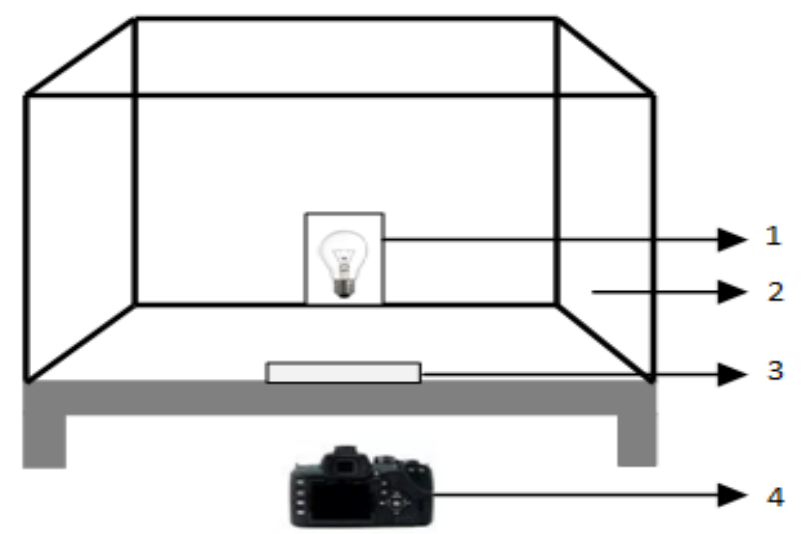

Fig.-1: The Photo Tools Set of Contact Angle: (1) Lighting Source, (2) Carbon Paper, (3) Sample, (4) Digital Camera

Where the lights serve as a light source, carbon paper to darken the test chamber so that light becomes the focus, the digital camera used has a high resolution of $16 \mathrm{MP}$. To measure the contact angle, first, a line was drawn forming the angle between the fluid with the sample surface. Then determined the angle of contact using Corel draw as shown in Fig.-2.

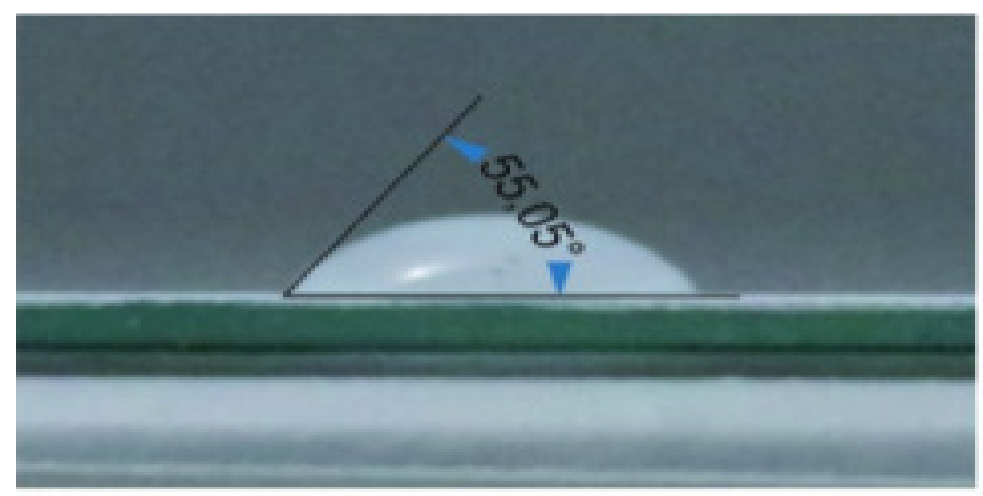

Fig.-2: Lines Withdrawal and Contact Angle with Corel Draw Framer

\section{Accelerated Weather Acceptability}

Accelerated weather resistance test was carried out by referring to the SNI 3546: 2009 emission wall paint. Following the treatment stages as follows: first, the test plate was painted on the glass substrate, then input the plate into the test tool of accelerated weather resistance by adjusting $100 \%$ of relative humidity temperature for 4 hours until reaching $40^{\circ} \mathrm{C}$. Once the desired conditions were obtained, then observations must be conducted. Emulsion wall paint was considered passing the test whenever it met the quality requirement which was colored and unpeeled.

\section{Chemical Characterization pH Measurement}

The $\mathrm{pH}$ measurements were performed to test the degree of acidity or alkalinity by using $\mathrm{pH}$ meters. Waterbased paint pH must be in accordance with the SNI 3546: 2009 emission wall paint, which was pH 7-9.5. The measurement process was carried out by dipping the $\mathrm{pH}$ meters into a mixture of water-based paint solution with additives and undertaking the direct observation by reading the listed scale at $\mathrm{pH}$ meters. 
RASĀYAN J. Chem.

Vol. 11 | No. 3 |1277 - 1285 | July - September | 2018

\section{Resistance for Alkali}

The alkali resistance test was carried out in accordance with the SNI 3546: 2009 emission wall paint. The test stages were first the sample was soaked with $\mathrm{NaOH}$ for 1 hour, then rinsed with distilled water, next let it dry for 30 minutes, and immediately observed. If there was no change in color, bubbles, shrinking, calcification or peeling, then the sample certified passing the SNI standard.

\section{Surface Morphology}

To detect the morphology of the sample layer that has been dried on the glass substrate, optical microscope MD 2800x with 1200x magnification was utilized.

\section{Analysis of Physic Characterization Density Measurement}

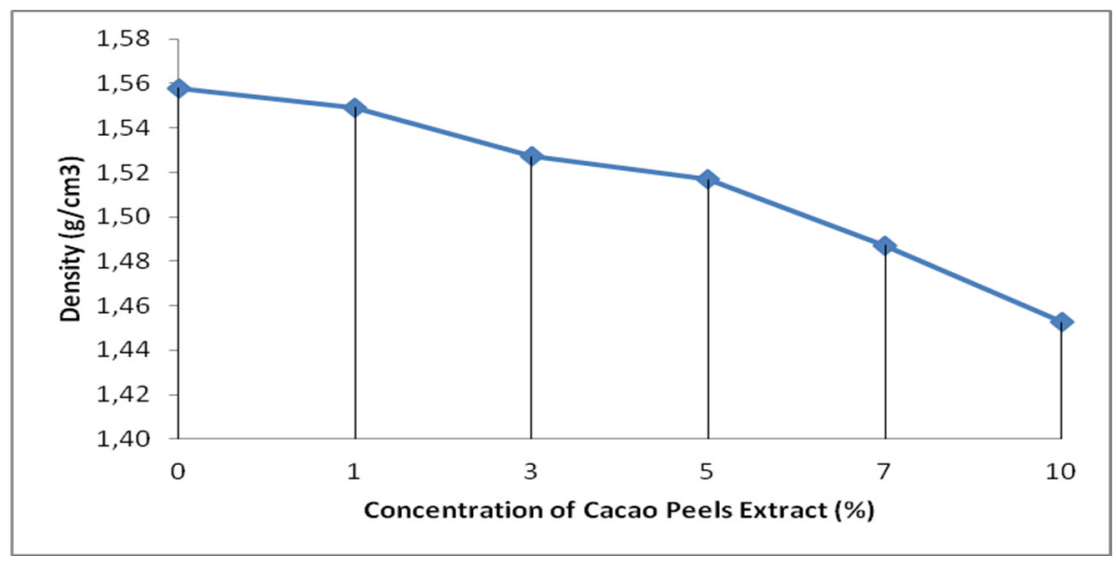

Fig.-3 : Graph Analysis of Density

According to Fig.-3, it can be seen that the increase in added additive concentration leads to significantly decreased density. Here, it shows that the paint becoming better as it leads to the specified SNI standard of $1.2 \mathrm{~g} / \mathrm{cm}^{3}$, where initially before the paint mixed with the additives has 1.56 of density high, whereas after being mixed with additive concentrations ranging from $1 \%, 3 \%, 5 \%, 7 \%$ and $10 \%$, the density decreases significantly into 1.55-1.45. This condition occurred due to the dilution of the paint solids after being added with the additive of cacao peels extract. High-density paint should be suspected as it contains a lot of fillers which are typically used to reduce paint production costs and increase the lid strength by reducing the use of pigments ${ }^{11}$.

\section{Analysis of Contact Angle}

The influence of additive concentration on cacao peels extract towards the angle contacts can be seen in Fig.-4. From Fig.-4, it can be analyzed that after conducting the accelerated weather resistance test, the contact angle decreases slightly compared to without accelerated weather resistance. It is due to the sample has been warming for a period of time which is equivalent to 600 hours of being exposed to Ultra Violet (UV) rays on the use of 1 (one) month. It also can be seen from this figure that the sample contact angle has increased from $74.45^{\circ}$ to $127.89^{\circ}$ in the addition of additives with concentrations of $1 \%$ and $3 \%$ compared to water-based paint contacts without the additive additions with of $51.59^{\circ}-55.05^{\circ}$ contact angles. However, in the additives addition with $5 \%, 7 \%$, and $10 \%$ concentrations, there is a decrease in this contact angle. Wheres in the additives addition with $3 \%$ concentration, the contact angle increases to $127.89^{\circ}$, so that the paint becomes hydrophobic with $90^{\circ}-150^{\circ}$ angle. As for the additive addition of 5\%, 7\% and $10 \%$ concentration, the obtained contact angle decreases, so the paint is becoming more hydrophilic, with the contact angle between $10^{\circ}-90^{\circ 12}$. 
In a mixture of water-based paint with $3 \%$ additive concentration has a contact angle of $127.89^{\circ}$, with the absence of the warming treatment condition of the accelerated weather resistance test. Whereas after the warming treatment of weather-accelerated test performed, a contact angle of $127.26^{\circ}$ is obtained. The hydrophobic properties obtained by the addition of $3 \%$ additives is effective for the presence and the absence of heating onto the accelerated weather resistance test. For more details, a surface is said to be hydrophobic if there is dirt on it, and then when it is exposed to water, the dirt will be dispelled by rolling on the surface ${ }^{13}$.

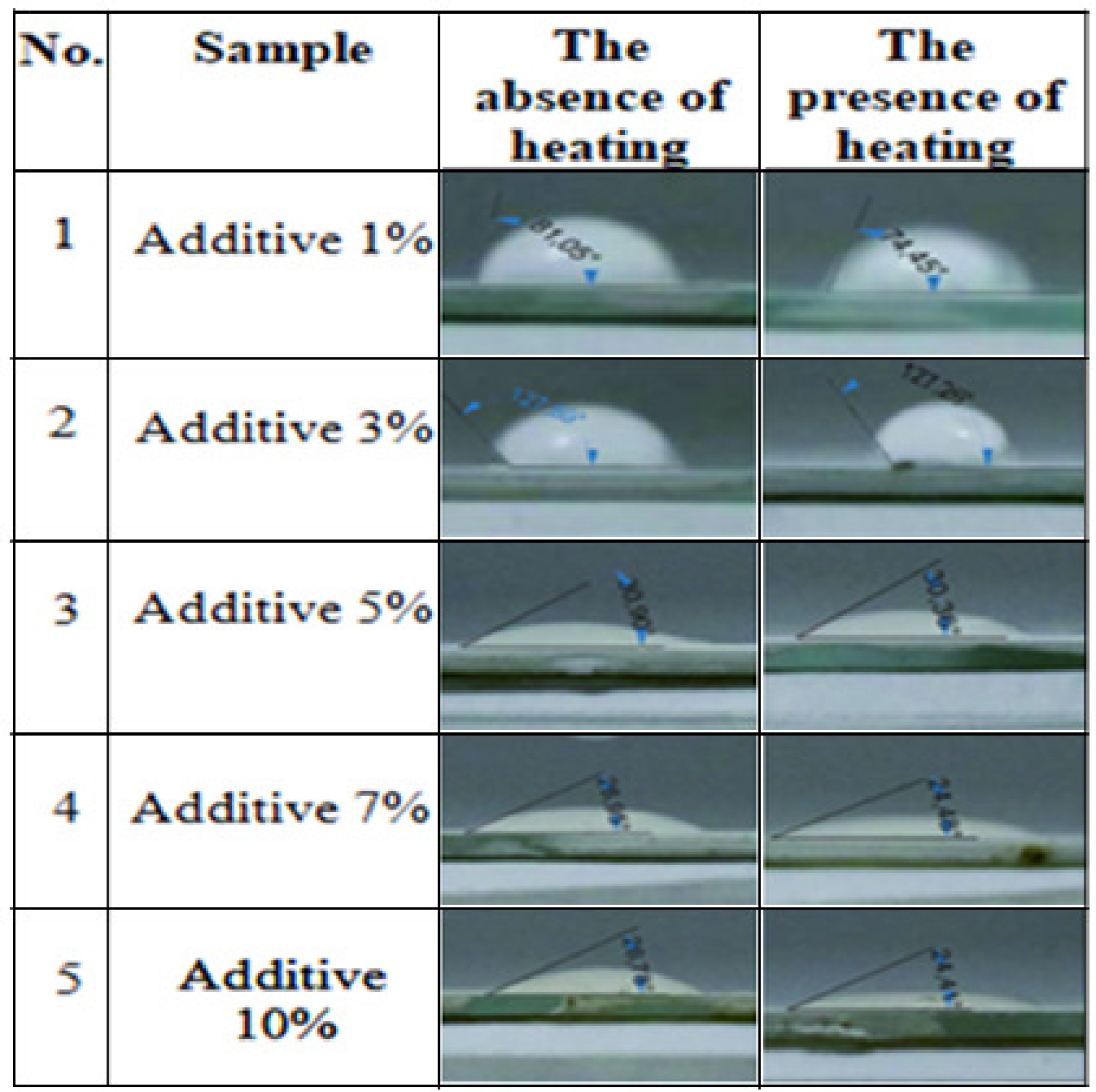

Fig.-4: Contact Angle

\section{Analysis of Accelerated Weather Accuracy}

After conducting an accelerated weather resistance test on the sample was performed the results were compared with the sample before being tested as shown in Fig.-5. The weather resistance factor is a parameter that can be used as a guide to the emulsion wall paint quality. Based on Fig.-5, there is no significant change in the color of the sample after experiencing an accelerated weather for the duration of 4 hours with $100 \%$ relative temperature and $40^{\circ} \mathrm{C}$ of sample temperature, and also the absence of wrinkles. This is in accordance with the standard of SNI 3546: 2009 emission wall paint. This states that the waterbased paints with varied concentration of cacao peels extract additive addition of 1\%, 3\%, 5\%, 7\% and 10\% are resistant to weather both day and night with the temperatures $(20-50)^{\circ} \mathrm{C}$ for at least 600 hours and shows the absence of calcification, discoloration and flaking. It is expected that hydrophobic bonding occurs where tannin becomes the growth inhibitor, so many microorganisms can be inhibited by this tannin growth ${ }^{6}$. And then this due to a hydrophobic interaction between nonpolar groups of protein in the water-based paint 
RASĀYAN $J$. Chem.

Vol. 11 | No. 3 |1277 - 1285 | July - September | 2018

(from amino acids having non-polar side chains) and tannins (benzene rings). The dominant strength of this bond is hydrogen bonding and hydrophobic interactions ${ }^{14}$.

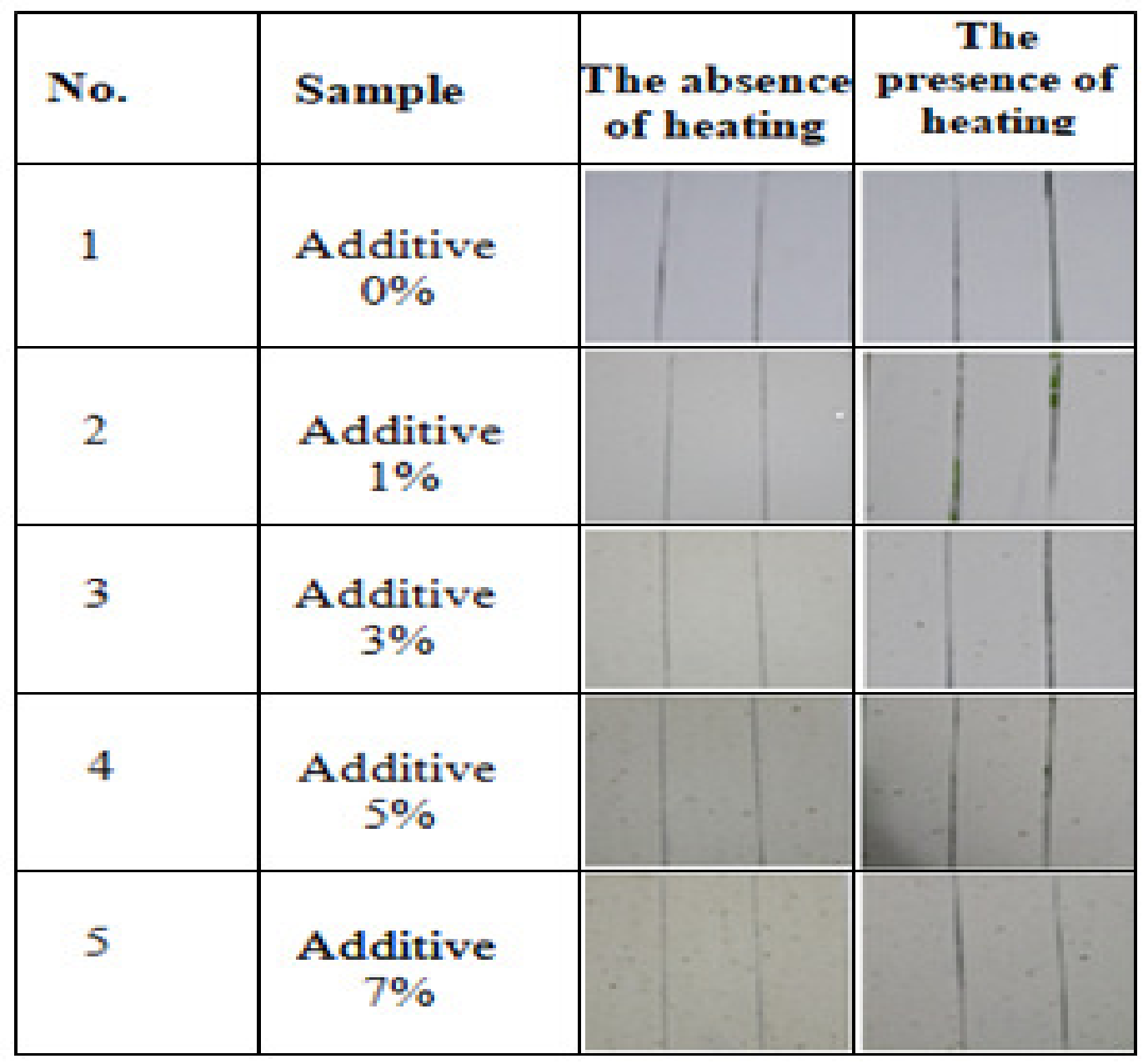

Fig.-5: Analysis of Accelerated Weather Accuracy

\section{Analysis of Chemical Characterization pH Measurement}

From Fig.-6, it can be seen that the increase in the additive concentration employed leads to significant $\mathrm{pH}$ reduction, where by the $\mathrm{pH}$ of the water-based paint prior to the additive addition is 8.89 . It is due to the additives of cacao peels extract is acidic with $\mathrm{pH}$ of 5.38. In the addition of $1 \%$ and $3 \%$ additives, the the sample $\mathrm{pH}$ is still in the $\mathrm{pH}$ range of 8.14 and 8.05 . On the other hand, in additives addition of $5 \%, 7 \%$ and $10 \%, \mathrm{pH}$ in the $\mathrm{pH}$ range 7 , it becomes $7.62 ; 7.34$ and 7.13. In this context, the additives addition with concentrations of $1 \%, 3 \%, 5 \%, 7 \%$, and $10 \%$, there is no significant change on the paint $\mathrm{pH}$ where the water-based paint is still alkaline. The obtained $\mathrm{pH}$ range is still within the limits of SNI 3546:2009 emulsion wall paint between $\mathrm{pH} 7$ - 9.5.

As it is known that the concrete or wall to be applied has alkaline properties. Therefore, the water-based paint mixture with the additives used should be alkaline as well. Because without having the balance, then unwanted reactions can be occured such as calcification, peeling color change, bubbles, and wrinkles. So it can be stated that a mixture of water-based paint and an additive of $1 \%$ cacao peels extract to a safe $10 \%$ concentration is safely used on walls or brick walls. With the addition of cacao peels extract additives there is a significant decrease in $\mathrm{pH}$, because the cacao peels extract is acidic. However, the results of the cacao peels extract additive mixture (concentrations of 1\%,3\%, 5\%, 7\% and 10\%) with water-based paints are still alkaline and in accordance with the SNI. If the mixture is acidic it will damage the quality of the paint. ${ }^{12}$ 
RASĀYAN J. Chem.

Vol. 11 | No. 3 |1277 - 1285 | July - September | 2018

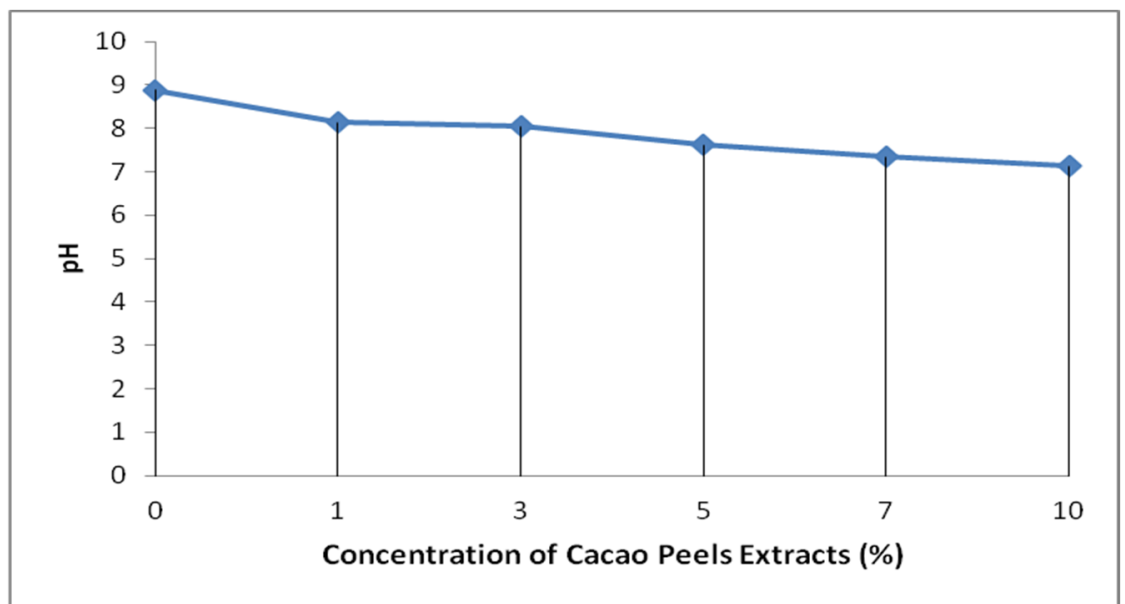

Fig.-6: Analysis of $\mathrm{pH}$

\section{Analysis of Resistance on Alkali}

The alkali resistance test was carried out by several stages: firstly immersing the sample with $0.1 \mathrm{~N} \mathrm{NaOH}$ for 1 hour, the second washed with aquades, the third dried for 30 minutes and obtained the results as in Fig.-7.

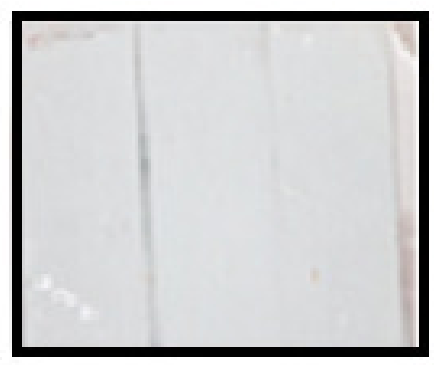

a

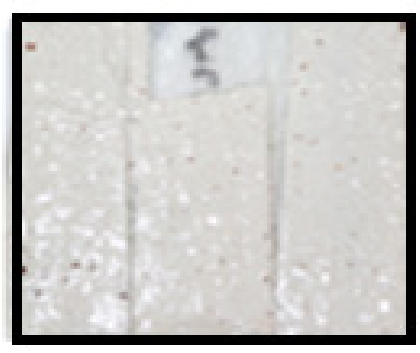

d

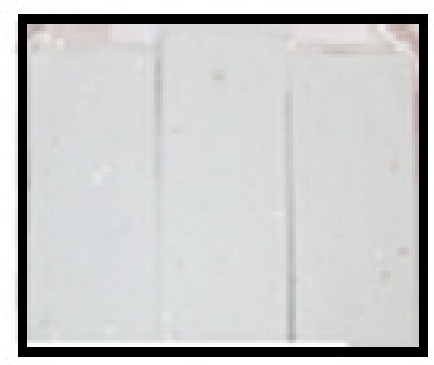

b

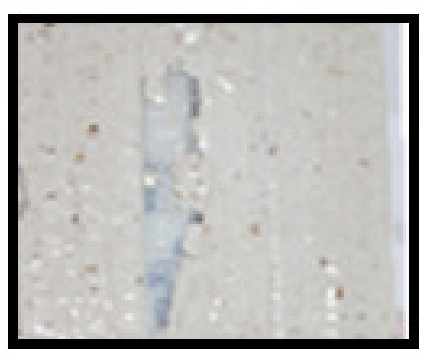

e

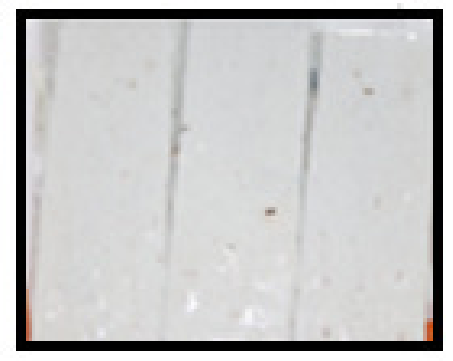

c

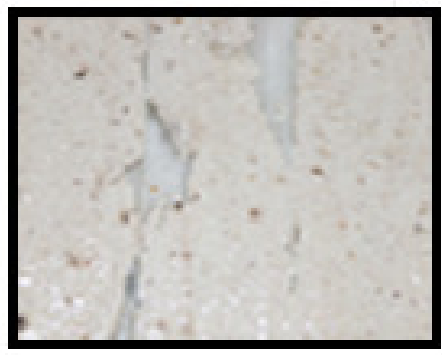

f

Fig.-7: The Resistance of Alkali additive: (a) $0 \%$; (b) $1 \%$; (c) $3 \%$; (d) $5 \%$; (e) $7 \%$; (f) $10 \%$.

From Fig.-7, it can be seen that the addition of $1 \%$ and $3 \%$ additives after performing the alkaline test is unchanged, whereas in additives $5 \%, 7 \%$ and $10 \%$, there is a color change, bubbles, shrinkage, calcification or peeling. It can be assumed that the addition of $1 \%$ and $3 \%$ additives concentration the paint can withstand the surface alkali properties and moisture. On the surface painting, there is usually a difficulty caused by moisture and alkaline properties of some surface types. Bricks, concrete and cement mixtures are alkaline, so the plastering result may contain alkaline as well, as it is carried over the surface during the drying process of the brick binder. On moist surfaces, alkali salts will damage the paint layer, causing the paint color subjects to change or fade. By preventing the alkali absorbing into the paint layer, the paint will be spared from calcification, and with the addition of $1 \%$ and $3 \%$ additives, it can prevent and pass the SNI emulsion paint 3564: 2009, against the alkali test. 


\section{Analysis of Surface Morphology}

The samples that have been spread on glass substrate either with or without conducting the test treatment are observed by using an optical microscope with 1200x magnification, where the obtained morphological results can be seen in Fig.- 8 .

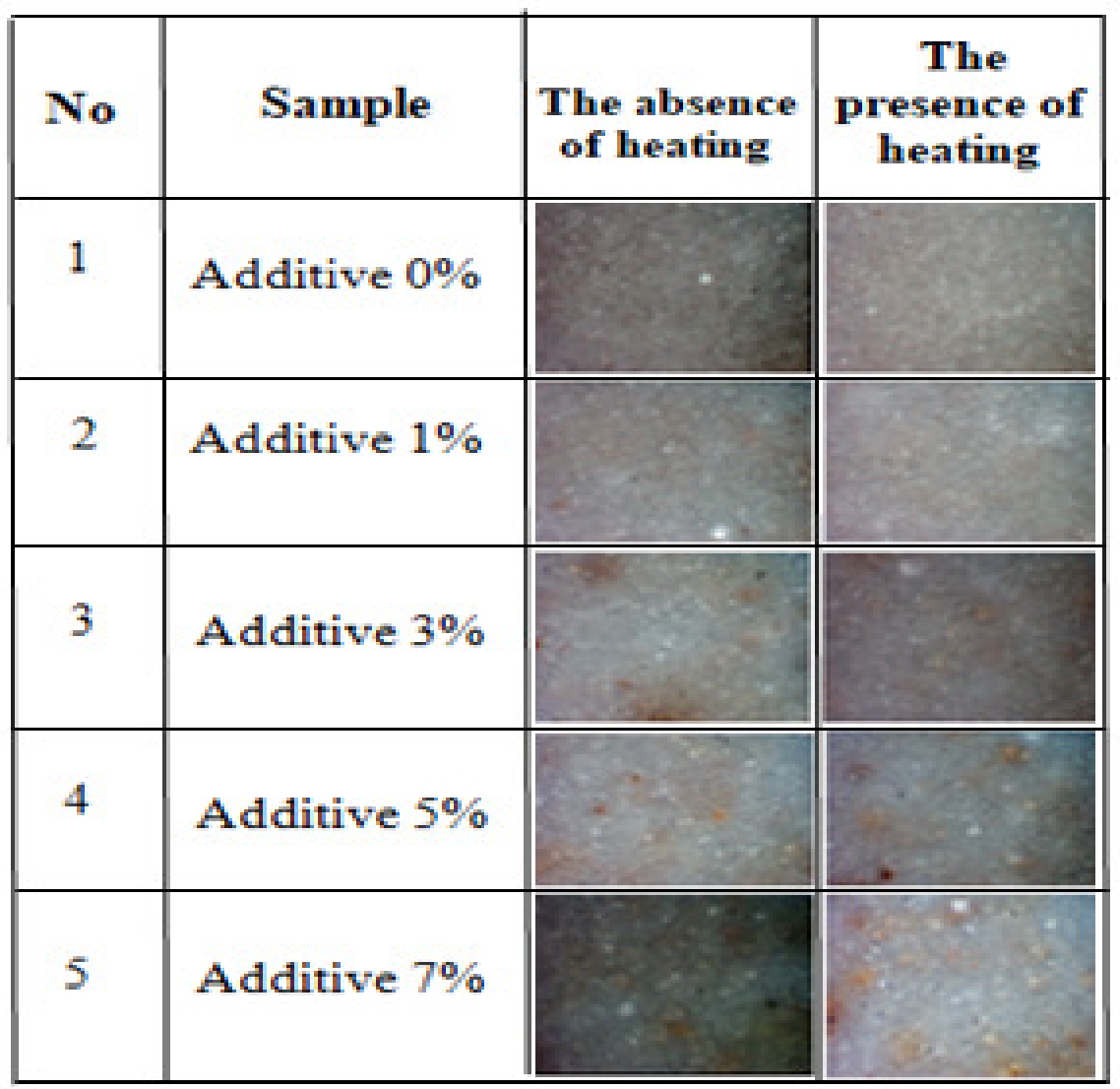

Fig.-8: Morphology of Sample Surface

Furthermore, from the morphological results in Fig.-8, it can be seen that water-based paint with the addition of cacao peels extract concentrations of $1 \%$ and $3 \%$ is the best percentage used in this test, both with accelerated weather resistance test and alkali test, and with the presence or the absence of treatment shows a flat morphology without holes or fractures.

\section{CONCLUSION}

Cacao peels extract is able to improve the hydrophobic properties of water-based paint. The increased concentration of cacao peels extracts additives used causes a significant reduction in $\mathrm{pH}$ and density. However, the paint is still alkaline and becoming better. Meanwhile, referring to the surface, there is no discoloration, liming, wrinkling and peeling with $1 \%$ and $3 \%$ additives addition on an accelerated weather resistance test. The hydrophobic properties are obtained from the addition of $3 \%$ cacao peels extract additives, $\mathrm{pH} 8.05$, and $1.53 \mathrm{~g} / \mathrm{cm}^{3}$ density with the largest contact angle of $127.89^{\circ}$ in the absence of heating and $127.26^{\circ}$ in the presence of heating. Additives of $1 \%$ and $3 \%$ concentrations do not change in color, bubble, shrinkage, calcification or exfoliation on the alkaline test, and also on accelerated weather resistance test with flat morphology and have no holes or fractures.

\section{REFERENCES}

1. L.C. Vriesmann, R.F. Teófilo, C.L.O. Petkowicz, LWT - Food Sci. Technol., 49, 108(2012), DOI: 10.1016/j.lwt.2012.04.018

2. H.X. Phong, P.T. Quan, N.N. Thanh, N.T.P. Dung, Can Tho Univ. J. Sci., 1(2016), DOI: 10.22144/ctu.jsi.2016.001 
RASĀYAN J. Chem.

Vol. 11 | No. 3 |1277 - 1285 | July - September | 2018

3. Y. Yetri, Emriadi, N. Jamarun, Gunawarman, Rasayan J. Chem., 9, 716(2016)

4. R.R. Utami, , S. Supriyanto, S. Rahardjo, R. Armunanto, Agritech, 37,88(2017), DOI: http://dx.doi.org/10.22146/agritech.10454

5. Y. Soro, A. B.B. Kassi, F. Bamba, Rasayan J. Chem., 5, 332(2012)

6. M.N. Mailoa, M. Mahendradatta, A. Laga, N. Djide, Int. J. Sci. Technol. Res., 3, 236(2014), DOI: 10.1023/A:1026206511084

7. W. S.B. Dwandaru, Z.M.C. Putri, E. Yulianti, J. Inotek., 20, 1(2016).

8. P. Monk, Physical Chemistry: Understanding our Chemical World, Jhon Wiley \& Sons Ltd, England. p.423-445(2004), DOI: 10.1017/CBO9781107415324.004

9. U. Lusiana, H.A. Cahyanto, Biopropal Ind., 5, 45(2014).

10. L. Zhou, S. Xu, G. Zhang, D. Cai, Z. Wu, Appl. Clay Sci., 132-133, 290(2016), DOI: 10.1016/J.CLAY.2016.06.015

11. S. Pal, V. Contaldi, A. Licciulli, F. Marzo, Coatings, 6, 48 (2016), DOI: 10.3390/coatings6040048

12. M.A. Karim, J.P. Rothstein, H.P. Kavehpour, J. Colloid Interface Sci., 513, 658(2018), DOI: 10.1016/j.jcis.2017.11.075

13. H.J. Ensikat, P. Ditsche-Kuru, C. Neinhuis, W. Barthlott, Beilstein J. Nanotechnol., 2, 152(2011), DOI: $10.3762 /$ bjnano.2.19

14. D.S. Liantari, J. Majority, 3, 27(2014)

[RJC-4017/2018] 